\title{
LA PANDEMIA DEL COVID-19 COMO EXPERIENCIA \\ LÍMITE DEL SENTIDO DE LA EXISTENCIA
}

DEL SER HUMANO POSMODERNO

\section{The Covid-19 pandemic as a limit \\ experience of the sense of existence \\ of the post-modern human being}

\author{
Remberto ORTEGA GUIZADO* \\ Investigador independiente, Panamá, República de Panamá \\ remberto04@gmail.com \\ Código Orcid: https://orcid.org/0000-0003-1259-1808
}

\begin{abstract}
Resumen
Después que el Director General de la Organización Mundial de la Salud (OMS), Tedros Adhanom Ghebreyesus, declarara la situación de pandemia el 11 de marzo de 2020, el mundo cambió pues, el Covid-19 provocó que, la sociedad posmoderna se pregunte sobre la existencia, sobre su sentido, sobre su fin. Sin embargo, una vez más, lo que vuelve a inquietar no es la búsqueda de una respuesta conceptual, sino una en cuanto experiencia existencial humana. Este artículo, basado en una investigación bibliográfica, presenta una aproximación filosófica de la pandemia del Covid-19 como experiencia límite del sentido de la existencia del ser humano posmoderno, que desvela la gran crisis ética y humana que caracteriza a la posmodernidad, y que por medio de la hegemonía de marcos conceptuales ha colocado a miles de seres humanos en la indigencia existencial. Por ello, dicho trabajo se delimita a la experiencia humana en este contexto; lo cual se hace desde lo ontológico existencial, sin que ello implique necesariamente estructuras intrínsecas al ser, como una búsqueda categorial sino más bien que lo ontológico se enraíza en la existencia; de tal manera que, se hace alusión a la obra de Butler (2006b) para tratar de evitar que la elucubración filosófica se quede en lo conceptual nominal, desvirtuando el enfoque existencial.
\end{abstract}

\section{Palabras clave}

Pandemia, vulnerabilidad, marcos hegemónicos, desnudez del ser, filosofía existencial, rostro.

Forma sugerida de citar: Ortega, Remberto (2021). La pandemia del Covid-19 como experiencia límite del sentido de la existencia del ser humano posmoderno. Sophia, colección de Filosofía de la Educación, 30, pp. 273-296.

* Ingeniero Industrial, filósofo y especialista en Proyectos de Desarrollo Social. 


\begin{abstract}
After the Director General of the World Health Organization (WHO), Tedros Adhanom Ghebreyesus, declared the pandemic situation on March 11, 2020, the world changed because, Covid-19 caused postmodern society to wonder about existence, on its meaning, on its end. However, once again, what is disturbing again is not the search for a conceptual answer, but one as a human existential experience. This article, based on a bibliographic research, presents a philosophical approach to the Covid-19 pandemic as a limit experience of the meaning of existence of the postmodern human being, which reveals the great ethical and human crisis that characterizes postmodernity, and therefore Through the hegemony of conceptual frameworks, it has placed thousands of human beings in existential destitution. For this reason, this work is limited to human experience in this context; which is done from the existential ontological, without necessarily implying intrinsic structures to being, as a categorical search but rather that the ontological is rooted in existence; in such a way that, allusion is made to the work of Butler (2006a) to try to avoid that the philosophical elucubration remains in the nominal conceptual, distorting the existential approach.
\end{abstract}

Keywords

\title{
Introducción
}

Cuando se trata de filosofar sobre la existencia, son muchos los senderos que se pueden recorrer, sin embargo, uno de los planteamientos más interesantes se encuentra en la obra de Arendt (1968) y que, sirve como punto de partida para la reflexión sobre la que versa este artículo y que reza:

Descartes ya había planteado el problema de la realidad en un sentido completamente moderno - para resolverlo en un sentido enteramente tradicional- La pregunta: si el Ser en tanto que tal es, es moderna: la respuesta, cogito ergo sum cae en el vacío; pues, como acertadamente lo advirtió Nietzsche, no prueba la existencia del ego cogitans sino a lo sumo la del cogitare. Dicho de otra manera, el Yo pienso no produce jamás el Yo verdaderamente viviente, sino solamente un Yo pensado. Esto es lo que sabemos a partir de Kant (p. 52).

Con base en lo que Arendt expresa, surge el turbador cuestionamiento sobre el ser pensado desde lo categorial y lo que la experiencia del viviente conlleva, es decir, la pregunta sobre la existencia vuelve a inquietar no en cuanto pregunta sino en cuanto experiencia existencial humana y es que después que el Director General de la Organización Mundial de la Salud (OMS), Tedros Adhanom Ghebreyesus, declarara la situación de pandemia el 11 de marzo de 2020, las cosas han cambiado pues, el Covid-19 parece exceder cualquiera de las muchas teorías que nacen de espíritus que, apegados a categorías nominales que se fundamentan y satisfacen en 
esquemas de análisis, de experimentación controlada, de planeación y previsión; sobre todo el de las ciencias positivas se han visto superados.

En este orden de ideas, es inevitable no colegir que la humanidad ha tenido que reconocer que la rancia naturaleza, inconquistable, cambiante, inaprehensible, se ha confrontado con la fragilidad y vulnerabilidad que entraña la existencia humana; que no solo ha amenazado los complejos y desgastados sistemas económico-políticos tradicionales, sino que ha ido más allá al romper con supuestos categoriales que han conducido a un estado de histeria y paranoia del pensamiento humano. Luego, parafraseando a Arendt (1968), es dable el advertir como el ser humano pensado no necesariamente es y agota al ser humano verdaderamente viviente.

Este artículo, basado en una investigación bibliográfica, presenta una aproximación filosófica de la pandemia del Covid-19 como una experiencia límite del sentido de la existencia del ser humano posmoderno. Para ello se seguirá una estructurado de reflexión que versa sobre tres grandes momentos: en el primero se reflexionará sobre lo categorial y lo existencial en la experiencia humana; en la segunda sección se presenta el estudio sobre la vulnerabilidad y el encuentro con el otro; la tercera parte trata sobre el ejercicio del poder y la invisibilidad categorial; para posteriormente finalizar con algunas conclusiones.

Es necesario advertir que, este trabajo se delimita a la experiencia humana en el contexto latinoamericano; lo cual se hace desde lo ontológico existencial, sin que ello implique necesariamente estructuras intrínsecas al ser, como una búsqueda categorial sino más bien que lo ontológico se enraíza en la existencia; de tal manera que, se hace alusión a la obra de Butler (2006a) para tratar de evitar que la elucubración filosófica se quede en lo conceptual nominal, desvirtuando el enfoque existencial, y que de esa manera se evite apelar a la responsabilidad, ya sea del ser humano como individuo o bien sea en su componente social desde el aparato político y económico. Es decir, la ontología a la que se hace alusión no es unívoca conceptual desde lo tradicionalmente aceptable, sino más bien desde lo equívoco.

Se propone una deliberación desde lo ontológico existencial, desde las situaciones límites y las condiciones humanas como la fragilidad, la necesidad y la vulnerabilidad que experimenta todo ser humano. Para ello, teniendo como hilo conductor el pensamiento de Butler (2010), se pretende realizar una reflexión de la pandemia: como experiencia límite del sentido de la existencia del ser humano posmoderno.

La visión ontológica que se presenta como hilo conductor de esta abstracción filosófica, sigue algunas de las ideas de Butler (2010) al expresar que: 
Hablar de 'ontología' a este respecto no es reivindicar una descripción de estructuras fundamentales del ser distintas de cualquier otra organización social o política. Antes, al contrario, ninguno de estos términos existe fuera de su organización e interpretación políticas (p. 15).

Esta crisis que no es solo sanitaria, sino que es ética y profundamente humana, reclama una reflexión pues, luego que se cumplan los plazos y se logre aplanar la curva de contagios, la humanidad inevitablemente deberá reflexionar y decidir sobre si el virus evolucionará hasta convertirlo en la excusa que aumente y valide la miseria humana, el olvido del otro, la supremacía de lo económico por encima de la existencia, la banalidad del mal.

Con base a lo antes mencionado, no faltan los expertos que siguen enfocándose en elementos tangenciales como la reinvención de la guerra fría, cambios en el sistema financiero y bursátil, que se traducen en cambios radicales en el escenario geopolítico, con nuevos puntos de fricción entre superpotencias o replanteamientos de las figuras supranacionales, entre otras que, siguen siendo discursos y conjeturas todas ellas que, evidencian una crisis de lo humano. $Y$ es que a pesar del dolor y la pena experimentada a nivel mundial, no se ha planteado aún un proceso de reconstrucción que reduzca la brecha entre poderosos y olvidados, entre los sujetos validados y los carentes de dignidad, porque se insiste en volver a una normalidad donde no coexiste una empatía con la honestidad, compromiso y responsabilidad, con el respeto a los proyectos de vida derivados de la propia historia personal y mucho menos con la salvaguarda de la promoción de relaciones entre pares, entre iguales, como personas dignas.

\section{De lo categorial a lo existencial de la ontología}

Es necesario tener en cuenta que, tal como lo advierte Vélez (2015), en los últimos años la humanidad ha sido testigos de lo que se ha denominado en algunos círculos académicos como la flexibilidad de la noción de ontología producto de una multiplicidad y diversidad de teorías y concepciones ontológicas que no se limita al campo filosófico de manera exclusiva, sino que se observa en las más disímiles disciplinas, por ejemplo en el ámbito de lo psicológico, gerencial, ingenieril, biomédico, informático, sistémico entre otros tantos, lo que nos proporciona la impresión de estar viviendo un renacimiento ontológico.

Esta proliferación ha traído consigo una interminable batalla donde se busca delimitar de la manera más certera los diferentes dominios 
de estudio o campos de acción, propugnando especificidad, autonomía e independencia de la propia ontología que amenaza con un desconocimiento exacto del qué, para qué y cómo del sustento de cada una de estas derivaciones. Por ello se hace imperante el establecer claramente el tipo de ontología que estará guiando esta reflexión.

En un artículo de la Revista Sophia № 17 titulado La Ontología de la Educación como un referente para la comprensión Ortega y Fernández (2014) plantearon que:

La certeza de que la educación debe entenderse no como algo abstracto sino como algo concreto que es, nos obliga a reconocer que la misma solo es posible en el ser humano. Luego, es un acto humano porque solo el hombre parte de la pregunta, en un esfuerzo por aprehender el mundo (p. 41).

La idea principal sobre la ontología que ambos autores expresan se puede utilizar como base para hacer referencia al hecho de abordar esta reflexión como una situación existencial límite con un asidero en una ontología existencial; porque al igual que los autores plantean que la educación no es algo abstracto porque ocurre en lo concreto del ser humano, así también la situación límite del miedo y la vulnerabilidad ocurren en un ser existente y concreto que también se pregunta por el sentido que tiene este sufrimiento, esta vulnerabilidad, esta pandemia y todo ello en su afán de aprehender el mundo.

No obstante, una concepción más profunda de este término exige pensarlo desde lo etimológico. Y es que, según Gutiérrez Sáenz (1999), la ontología se puede definir como:

El logos o conocimiento del ente. Y de forma técnica se la suele definir como la ciencia del ente en tanto que ente. Ente es todo aquello que tiene ser; del mismo modo que llamamos estudiante a toda persona que estudia, o amante al que ama, ente es el término que podemos utilizar para referirnos a las cosas en la medida en que estas poseen ser (pp. 56-57).

Sin embargo en este artículo, más allá del concepto categorial y etimológico, se hace referencia a una ontología desde la experiencia, desde la existencia no solo nominal, es por ello que, es importante retomar elementos de valiosos de la filosofía existencial y de la ética del encuentro, tal como lo propone Judith Butler (2010), quien ha generado una nueva propuesta filosófica que se enmarca en la tesis central de que se es humano en cuanto seres en relación pero no solo una relación con un igual sino con lo otro, inclusive con lo que queda fuera de las categorías convencionales de lo humano, es decir, con lo no humano. 
Es así como la ontología de la vulnerabilidad que platea Butler (2006a), se convierte en un adecuado elemento conceptual-existencial para elucubrar sobre la pandemia como situación límite, que obliga a pensar no solo en el virus, sino que también provoca interpretar todo el tejido social local, regional y mundial.

En este orden de ideas y parafraseando a Santamaría (2020) la reflexión sobre la vulnerabilidad personifica un remesón a las estructuras categoriales en muchos de los campos humanos que exige plantearse la pregunta sobre el enfoque aplicado a lo ontológico, pues para algunos la hegemonía de sistemas y formas de pensar enraizados en una ontología categorial, es, sin duda, uno de los elementos causantes de este estado de paranoia colectiva donde los sistemas sociales, culturales, morales y económicos no han sido capaces de asegurar el bienestar del ser humano, al punto de sumergirnos en una situación límite.

\section{¿Cómo entender el límite en la experiencia humana?}

Todos los seres humanos, antes o después experimentan situaciones que, parafraseando a Jasper (1950), constituyen los marcos de la vida espiritual interior del hombre y de su actividad práctica. Estos marcos forman los límites de la existencia, más allá de los cuales se extiende la nada. Los marcos de la propia existencia se hacen existencialmente palpables cuando experimentamos miedo, sufrimiento, vulnerabilidad, lucha, insatisfacción y muerte. Sin embargo, tal vez lo más relevante en estas situaciones es su carácter de fatalidad y de universalidad, el ser humano no puede evitarlas; su superación significa la pérdida de la existencia.

Entonces, siguiendo lo expresado en el párrafo anterior, es dable el colegir por qué es necesario entender que la pandemia del Covid-19 constituye una situación límite y es que, esta ha generado que miles de personas en todo el mundo experimenten miedo, angustia vulnerabilidad.

Prueba de ello se puede encontrar en el artículo de La Gaceta de Salamanca (2020) en la que se evidenció el impacto psicológico del Covid-19 y la situación de confinamiento derivada del estado de alarma decretado por el Gobierno español para combatir la propagación del virus. Dicho estudio reveló que las personas entre 18 y 39 años son los que presentan más ansiedad, depresión y síntomas somáticos, así como un mayor sentimiento de soledad y falta de compañía.

Más allá de las cifras estadísticas y porcentuales, la experiencia de la pandemia del Covid-19, en sus múltiples concepciones constituye una 
tribuna sobradamente dilatada, flexible y recia como para servir de punto de quiebre y escenario perfecto para la revisión de la razón solipsista de los grandes sistemas hegemónicos de pensamiento, para reunirse con lo que había condenado a la excentricidad como: sentimientos, voliciones, apetencias, deseos, miedos, pasiones, necesidad, en cuanto integrantes del ser humano. Es dable entonces admitir, como afirma Butler (2006a), la necesidad de salir de lo estrictamente categorial-nominal se hace imperativo para poder provocar una irrupción ontológica desde la vulnerabilidad que sirva de eje transversal en la reflexión de la experiencia.

La reflexión desde la experiencia hace posible que converjan todos aquellos elementos subjetivos de la existencia de y en cada ser humano que le da ese grado de objetividad a la persona humana, pues la misma es también alma, conciencia, mente y gracias a ello está en la capacidad de adentrarse en el proceso de comprensión de lo real.

\section{La necesidad de una reflexión enraizada en la experiencia de la propia existencia}

Comprender lo real, desde lo que se experimenta y se comparte con el otro no ocurre desde lo académico, numérico o nominal sino desde la existencia concreta, desde el cuerpo, desde la mortalidad que no puede ser simplemente categorizada. Esta idea de la imposibilidad de la categorización de la mortalidad se observa en toda la obra de Butler (2006a), quien de alguna manera plantea que se necesario experimentar la propia mortalidad, vulnerabilidad, indigencia, fragilidad, heteronomía, ambigüedad. Esto se puede comprender mejor en la siguiente frase de Butler (2006a): "desde la piel, la carne, los sentidos, la memoria, el deseo, todo ello nos expone, nos saca de nosotros mismos y nos pone frente al otro" (p. 36).

Lo mencionado con anterioridad permite entender que la existencia no se vive solo desde lo privado y lo incomunicable, sino que tiene un componente de responsabilidad y de comunicación que surge en el encuentro con otro en un lugar común que se comparte, al que se llama cuerpo. En términos de Butler (2006a):

El cuerpo no es del todo nuestro, no es algo privado sino público. Mi vida está implicada en otras vidas. Mi vida no es completamente mía. Venimos al mundo necesitados de una hospitalidad y esta condición vulnerable no puede eludirse, no puede ser superada (p. 44).

Si la experiencia de la vulnerabilidad es intrínseca a todo ser humano, como un componente esencial de la existencia misma, entonces 
es necesario plantearse la siguiente pregunta: ¿cómo se podría definir la vulnerabilidad dentro de esta reflexión?, misma que se busca responder en el siguiente apartado.

\section{La vulnerabilidad como constitutiva de la humanidad}

En el sitio oficial de International Federation of Red Cross and Red Crescent Societies (Federación Internacional de Cruz Roja y Media Luna Roja) (2020), se puede encontrar la siguiente definición de vulnerabilidad:

La vulnerabilidad puede definirse como la capacidad disminuida de una persona o un grupo de personas para anticiparse, hacer frente y resistir a los efectos de un peligro natural o causado por la actividad humana, y para recuperarse de los mismos. Es un concepto relativo y dinámico. La vulnerabilidad casi siempre se asocia con la pobreza, pero también son vulnerables las personas que viven en aislamiento, inseguridad e indefensión ante riesgos, traumas o presiones (p. 1).

De la definición anterior se puede centrar la atención en la idea de capacidad disminuida, porque esta disminución se enraíza en el hecho de todo ser humano está expuesto a diferentes situaciones como los desastres, enfermedades u otras que lo que hacen es violentar su existencia.

La violencia, parafraseando a Butler (2006b), puede ser considerada una experiencia legitimadora que reclama una ontología de la vulnerabilidad pues, ante el hecho de que todos los seres humanos tienen un cuerpo mortal que puede ser herido, todos están expuestos a la violencia que se traduce en vulnerabilidad. Es decir, la violencia puede ser entendida como causante de la vulnerabilidad y al exacerbarse esa vulnerabilidad provoca, según la literatura médica, una irrupción en la vida de un ser humano tan devastadora que se convierte en sufrimiento existencial, ya que hace referencia a la percepción de sin sentido, ansiedad y miedo ante la muerte.

Sobre este particular, es importante tener en cuenta la definición etimológica de esta palabra, pues si la vulnerabilidad es génesis de ese sufrimiento existencial en cuanto significa fragilidad, susceptibilidad de padecer daño o lesión. No obstante, yendo un poco más allá, es necesario recurrir a la etimología, tal como menciona Pacheco (2017): "el término - vulnerabilidad - procede del latín vulnus que puede entenderse como "herida" o "daño", abilis que puede equivaler a "que puede", y el sufijo dad que indica cualidad" (p. 7).

La definición etimológica aún puede ser comprendida de una mejor manera, como lo plantea el mismo Pacheco (2017): "la vulnerabilidad 
puede definirse entonces como cualidad que tiene alguien para poder ser herido o dañado" (p. 7). No obstante, también es importante denotar que no necesariamente la vulnerabilidad entraña una posición de pasividad y es que, algunas aproximaciones teóricas establecen que las personas vulnerables son aquellas que, por distintos motivos, no tienen desarrollada la capacidad para prevenir, resistir y sobreponerse de un impacto y, por lo tanto, se encuentran en situación de riesgo. Con lo cual se podría entender que ser vulnerable es cuestión de capacidad.

La idea final del párrafo anterior ha sido aceptada en muchos de los círculos académicos hegemónicos que, desconociendo un sentido de responsabilidad por el otro, se circunscribe a encerrarlo en sus propias capacidades, inclusive lo relegan al plano de lo volitivo. Luego es dable el que se escuchen afirmaciones populares como: jeres pobre porque quieres!, ¡sufres porque quieres! o bien ¡eres vulnerable porque quieres!

Es dable advertir que el discurso social hegemónico es el que está creando la realidad, en cuanto a que, inclusive, la experiencia intrínsecamente humana de la vulnerabilidad se ve cuestionada desde los espacios de ese poder que Butler (2006b) denuncia como el causante de que una persona, hasta cierto punto, se mueva en una realidad determinada, y al mismo tiempo legitima exclusiones a partir de normas sociales y produce cuerpos abyectos, que son inadmisibles, ininteligibles e ilegítimos.

En este orden de ideas, es lícito revisar la siguiente definición que plantea Villa (2001):

Vulnerabilidad es el riesgo o probabilidad de que un individuo, un hogar o una comunidad pueda ser lesionada o dañada a raíz de cambios en las condiciones del contexto en que se ubica o en virtud de sus propias limitaciones (pp. 3-4).

Sin embargo, ese riesgo solo podrá ser reconocido por otros en cuanto legítimo si ocurre dentro de un marco normativo hegemónico legítimo donde, parafraseando a Butler (2010), no pueden existir cuerpos ilegítimos, pues estos, si es que el sistema admite que existen, solo lo harán fuera de la norma ya que son inteligibles justamente como abyectos. Es aquí donde reside su falta de reconocimiento. La vulnerabilidad categorizada no puede ser la que rija este encuentro con el otro, sino la vulnerabilidad existencial, porque todos los seres humanos tienen la capacidad de experimentar la vulnerabilidad y esa vulnerabilidad no es conceptual sino existencial.

Solo una vulnerabilidad experimentada, admitida y reconocida es eje concatenado de la existencia humana como posibilidad de experi- 
mentar este dolor, que se vuelve una interrupción en el orden del ser. Es decir, cada ser humano que haya existido, existe o existirá, experimentará en mayor o menor grado esa vulnerabilidad que genera la violencia y es en esa vulnerabilidad donde se revela la manera en que la relación con el otro lo constituye, pues "la herida ayuda a entender que hay otros afuera de quienes depende mi vida" (Butler, 2006b, p. 14). Luego, lo humano surge en la desnudez del ser. No obstante, es necesario hacer un alto para entender esto de la desnudez del ser.

\section{El encuentro con el otro como experiencia desnudez del ser}

A lo largo de la obra de Levinas, este introdujo uno de los elementos más representativos del accionar filosófico y es el concepto del 'rostro'. Este concepto levinasiano no se refiere a una idea estética o de la plástica necesariamente, sino que estrictamente lo vuelve un equivalente de la desnudez. Verbigracia, una desnudez que se traduce en vulnerabilidad, siendo tal vez la experiencia límite de esta la muerte. Pero, la muerte no es mi muerte sino la muerte del otro y es que para Levinas (1994) "nos encontramos con la muerte en el rostro de los demás" (p.126).

Cuando el ser humano se encuentra con la muerte en el rostro del otro, este hecho lo interpela existencialmente y lo cuestiona sobre la responsabilidad que tiene de ello y es que, para Levinas la ética surge aquí, cuando el ser humano reconoce que la vida del otro es más importante que la suya, esto es lo que sublimemente lo hace humanos, porque no se asume único desde un egoísmo existencial, sino que se entiende en relación, en encuentro permanente, en una codependencia donde su propio ser necesariamente existe porque es reconocido por el otro que también lo valida.

La experiencia del Covid-19 ha permitido que todos los seres humanos experimenten su vulnerabilidad dentro de un espacio de tiempo que lo asfixia de manera personal, pero también la han visto reflejada en los otros con los que habitan este mundo; inevitablemente los enfrenta a cuestionarse sobre el tiempo, sobre la duración de este mal que le aqueja. Sin embargo, esta pregunta por la duración, por el tiempo, se vuelve una pregunta ética y existencial en cuanto se relaciona con otro, tal como lo expresa Levinas (1993):

...pensar el tiempo no como una degradación de la eternidad, sino como relación con aquello que, siendo de suyo inasimilable, absoluta- 
mente otro, no se dejaría asimilar por la experiencia, o con aquello que, siendo de suyo infinito, no se dejaría comprender (p.69).

La no comprensión hace referencia al límite de lo categorial-nominal; no obstante, desde lo existencial la asimilación ética provoca que el ser humano se pregunte: ¿he experimentado mi humanidad?, o, mejor dicho: ¿los seres humanos han experimentado esa humanidad de la que habla Levinas al encontrase con el dolor que se refleja en el rostro de ese otro?

\section{De la multitud de caras a la invisibilidad del rostro}

En el sitio web de la Organización Panamericana de Salud (PAHO siglas en inglés $)^{1}$ se puede encontrar una gran cantidad de información sobre la pandemia del Covid-19 a nivel de cifras y es curioso observar cómo las estadísticas principales hacen referencia a tres métricos principales a saber:

- La cantidad de días transcurridos desde la detección del primer contagiado en América.

- Los casos confirmados de contagiados.

- Los casos de defunciones confirmadas.

Todas estas cifras y estadísticas son importantes para aquellos que, en términos de cuantificar, hacen proyecciones, preparan modelos matemáticos predictivos y deductivos, utilizando estos insumos. Sin embargo, no se trata de contabilizar el sufrimiento por medio de las víctimas, sino de encontrar con un rostro, es decir con el ser humano concreto, que está más allá del número, porque desde la ética que ha planteado Levinas, la ética del encuentro con el rostro, cada ser humano en este momento histórico se le hace una pregunta sobre su responsabilidad hacia ese otro que sufre. Esta pregunta ética demanda una respuesta en singular y personal.

La respuesta a la pregunta ética va más allá de una teoría deontológica que fija normas que rigen la conducta y el desempeño en la esfera profesional, y este ir más allá ocurre porque es pregunta existencial que supera la prerrogativa del circulo profesional donde se determinan responsabilidades en relación con los actos ligados al campo laboral; porque como esboza Levinas (1994): "nos encontramos con la muerte en el rostro de los demás" (p.126).

Este encuentro con la muerte del otro, parafraseando a Levinas (2006), se vuelve pregunta ética que, partiendo del rostro del otro en su precariedad, en su vulnerabilidad, en su necesidad es para cada ser humano la tentación de matar y el llamado a la paz. Matarlo en cuanto a 
desentenderse de ese otro, relegarlo al olvido; o de paz, en cuanto sale a su encuentro, lo asiste, lo ayuda, se reconoce interpelado. Esta demanda de una respuesta es lo que los jefes de Estado, las grandes organizaciones mundiales han sentido y cada uno de ellos se está debatiendo entre la tentación de matar (desentenderse) o llenarse de paz (salir al encuentro).

La idea de paz y matanza en la ética de Levinas (2006), va más allá de la lucha que libran los profesionales de la salud contra el Covid-19 en los hospitales, clínicas, entre otros; sino aquella que se libra en los parlamentos, asambleas, cámaras de diputados, juntas directivas de organismos internacionales, organismos no gubernamentales, donde algunos buscan desentenderse del otro (matar) mientras que otros buscan la paz (salir a su encuentro).

La decisión de salir al encuentro o desviar la mirada se entrelaza con la ética, pero no solo con ella sino con la teoría del sujeto de derecho que se sustenta en la conceptualización jurídica de la vida humana. Este punto es el que, a la vista de Butler (2012), permite entender que el poder organiza la vida y dispone de ella, operando también sobre la precariedad, y decidiendo sobre las vidas que son o no dignas de duelo, de salvar o dejar perecer. En este sentido, es importante hacer alusión a Varsi (2017):

La vida es una, pero — sea biológica o social - adopta diversos estadios que merecen una regulación acorde con su estatus. Es esta esencia y forma como la vida se presenta en sociedad lo que permite categorizarla jurídicamente y de esto se encarga la teoría del sujeto de derecho. De esta forma se regula la vida humana en su verdadera esencia y dimensión; sin embargo, la biotecnología procreativa y genómica vienen alterando su clásica taxonomía, variándolo, al presentar nuevos actores en un mundo de relación (p.1).

La idea del sujeto de derecho es lo que ha venido definiendo muchas de las acciones emprendidas de tal manera que, a lo largo de toda la América, ha permitido observar que, aunque en el imaginario colectivo se piensa en igualdad de derechos o que todos son sujetos de derecho, nada más lejano de la realidad. Fernández (2009) expresa este constructo social mediante la siguiente afirmación:

En la experiencia jurídica —en la dimensión existencial— este ente o centro de referencia normativo no es otro que el ser humano antes de nacer o después de haberse producido este evento, ya sea que se le considere individualmente o como organización de personas (p. 3).

Esto que expresa Fernández, no necesariamente es cierto pues, aunque todos los seres humanos corren el riesgo de contagiarse con el 
Covid-19, compartiendo la experiencia de la vulnerabilidad, no todos son necesariamente considerados sujetos de derecho, pues siguen siendo juzgados desde los marcos hegemónicos conceptuales, donde lo importante puede ser la cifra (caras en plural) y no el rostro (el ser humano en su dignidad de persona).

\section{De lo políticamente correcto a un ejercicio del poder}

Esta disyuntiva entre mirar las caras y no ver el rostro, este juego de discursos donde se apela a lo políticamente correcto, hace entender que toda sociedad establece un sistema de significaciones que, en definitiva, es un sistema de reconocimiento, una especie de fraternidad de los iguales, de los que comparten la máscara, peor aún el club de los que respondiendo al check-list de los marcos ideológicos oficiales a los que son sometidos por la ontología social hegemónica, o como podría de alguna manera expresar Butler (2010), una sociedad donde se imponen las caras de aquellos a quienes se debe responder y de los que se tiene que ocupar.

La idea de la responsabilidad con unos cuantos que son legitimados dentro de los cánones del marco referencial hegemónico, una vez más reclama que se tenga en cuenta uno de los principales discursos de poder, que ha sido debidamente aceptado, y que platea la necesidad de la protección de la especie más que al individuo. Y es que, el poder como ejercicio tiende a conducir las posibles conductas y enmarcar el lugar correcto donde los individuos pueden accionar a través de una serie de categorías constituidas, tal como lo denuncia Foucault (2000) al decir que por medio de "métodos que permiten el control minucioso de las operaciones del cuerpo, que garantizan la sujeción constante de sus fuerzas y les impone una relación de docilidad-utilidad" (p. 141).

Esta relación de docilidad-utilidad se desarrolla dentro de esos marcos sociales morales, que en medio de la pandemia del Covid-19, hacen evidente que para aquellos que ostentan el poder hegemónico lo de menos es el sufrimiento, sino que lo importante es en qué lugar de la clasificación los situamos, porque los marcos visibilizan, humanizan, dan voz, pero también deshumanizan y condenan al olvido, a la indiferencia, al exterminio. En otras, como afirma Butler (2010): "los marcos morales distinguen las vidas que podemos aprehender de las que no" (p.17).

Toda esta discriminación legitimada entonces en un discurso de poder donde ya no se piensa solo en el individuo sino en la colectividad, no en el homo sino en el hábitat. Es más, este esquema de categorización 
de la humanidad como sujeto de derecho robustece la teoría del concepturus. Dicho término, según lo platea Varsi (2017), se refiere a:

...una institución propia del Derecho sucesorio y, en la actualidad, se ha llegado a zanjar doctrinal y jurisprudencialmente en el Derecho comparado que el mismo tiene vocación sucesoria, i.e. derecho a ser heredero o legatario. Tal es el caso contemplado por los códigos de Alemania, Bolivia, Colombia, Italia y Venezuela (p. 220).

El concepturus evidencia una vez más como el individuo pierde su rostro y se diluye en la especie, peor aún un discurso tan hegemónico donde la humanidad es ser jurídico ideal donde el genoma humano es patrimonio de la humanidad y, como tal, merece la más amplia protección propuesta está avalada por la Declaración Universal de los Derechos Humanos de las generaciones futuras y la Declaración Universal sobre el Genoma Humano y los Derechos Humanos. Es curioso que el mundo entero esté frente a un ejemplo palpable del ejercicio de poder que en su momento había denunciado Foucault (2000).

\section{De las pérdidas económicas a la desgracia de la moral que invisibiliza}

Establecido la existencia de categorías que humanizan o deshumanizan dentro de los marcos definidos por los grupos hegemónicos, entonces se puede dar cuenta que la verdadera desgracia del Covid-19 es que esos marcos han jugado con la vulnerabilidad de ese otro, sirviendo de barrera que les ha robado el derecho a siquiera ser dignos de reconocimiento.

Y es que, el Covid-19 ha generado toda clase de preocupaciones que, dentro de los marcos hegemónicos, han buscado cuestionar el accionar político en algunos países y regiones, tal como se puede leer en el siguiente extracto de un artículo que lleva por título: "El Covid-19 en América Latina: desafíos políticos, retos para los sistemas sanitarios e incertidumbre económica".

...la tradición presidencialista latinoamericana, los diferentes mandatarios han asumido una elevada exposición pública y un gran protagonismo, así como la dirección directa de la crisis que se avecina ...en muchos casos no tienen una red protectora al no poseer estos países unos sistemas administrativos y sanitarios eficaces y eficientes. Esta extremada personalización en la dirección de la crisis es una apuesta arriesgada: por un lado, tiene la virtud de construir un liderazgo fácil (...) por otro lado, expone al presidente a un claro riesgo: el de que, en caso de que la 
situación empeore, todo el desgaste recaiga sobre su persona (Malamud y Núñez, 2020, p. 1).

Este artículo evidencia hacia dónde la moral hegemónica invita a mirar y que, al mismo tiempo, invisibiliza o niega a otros en esta región, porque en Latinoamérica hay grupos humanos que, desplazados, indigentes eternos, siguen buscando nuevos sitios y nuevas oportunidades, nuevos marcos donde puedan existir, ser reconocidos; sin embargo, es curioso cómo han sido negados y cuando alguno de estos grupos humanos se atreve a levantar su voz, han sido callados violentamente, vetando su dignidad de persona.

Siguen siendo esos otros, los parias de una sociedad que cierra sus ojos ante el rostro del campesino, del indígena, del migrante, del negro, entre otros que hoy se encuentran fuera de los sistemas de salud, de educación, de seguridad social, pues no son legítimos hijos del marco dominante, aunque si vulnerables, de hecho, tal vez más vulnerables entre los vulnerables. Esto se nota de manera innegable en el artículo que se publicó en la página oficial de UNICEF (2020) Costa Rica y donde se señala que:

En América Latina y el Caribe, alrededor de 154 millones de niños y niñas, más del 95 por ciento de los matriculados, se encuentran temporalmente fuera de las escuelas cerradas a causa del Covid-19, informó UNICEF hoy basándose en datos de la UNESCO² (p.1).

Esas breves líneas del artículo de UNICEF, claramente expone cómo la vulnerabilidad de ese otro solo se puede hacer notar si se dice o se presenta desde los cánones del discurso que los marcos dominantes han preestablecido, este discurso no necesariamente devuelve la dignidad a ese otro pues sigue siendo cifra y no rostro.

El drama de los excluidos es tal que, aunque salidas brillantes de los diferentes grupos de poder apuntaron, por ejemplo, cerrar las escuelas y hacer que niños y jóvenes se acogieran a plataformas virtuales de aprendizaje, lo cierto es que esta medida solo evidenció lo paupérrimo y desgastado de los sistemas educativos públicos de las regiones Latinoamericana y caribeña que siguen retrasadas por varias décadas, porque como se expresa en la publicación de UNICEF (2020):

Aproximadamente el 90 por ciento de los centros educativos de primera infancia, primaria y secundaria de América Latina y el Caribe permanecerán cerrados los próximos días o semanas y el porcentaje va creciendo rápidamente. Esta situación, que podría extenderse más allá de lo ini- 
cialmente planteado, aumentará el riesgo de abandono escolar definitivo, especialmente para los niños y niñas más vulnerables (p.1).

Es necesario enfatizar lo que se expresa en la última línea del párrafo del artículo citado; 'niños y niñas más vulnerables'. No obstante, la pregunta que la moral hegemónica se hace no es si hay un alguien vulnerable o sufriente, sino más bien qué es el que sufre, es o no persona, es o no ciudadano, es o no similar a mí. En función de la respuesta, Butler (2010) acota, "la moral decidirá si esa vida debe ser llorada, porque desde un punto de vista moral la vida y la muerte existen siempre en relación con un marco determinado" (p. 22). Peor aún, no solo se trata de cómo te cataloga, sino que inclusive limita la existencia de la persona.

\section{De la invisibilidad categorial al existir con sentido}

La existencia validada por los marcos hegemónicos se circunscribe a límites definidos categorial y conceptualmente, es decir y parafraseando a Butler (2010), los marcos son los que deciden sobre las vidas que son dignas de duelo, las que son vivibles o normales. Esta experiencia de la visibilidad, durante esta pandemia, es la que hace legitima que algunos sujetos se les considere ciudadanos de derecho, y es que dentro de los marcos en los que han sido circunscritos se ha validado su existencia, su ser persona, su categoría de ser. Pero una gran mayoría sigue invisible aun cuando el discurso de la esfera pública habla de ellos permanentemente, aunque sin ellos.

La esfera pública hegemónica está constituida por lo que aparece, por lo que es representado, por lo que se considera, en un momento determinado, real. Pero, al mismo tiempo, como lo advierte Butler (2014), también hay en esta misma esfera de representación un ocultamiento, un desinterés, un olvido, una indiferencia, una negación, una prohibición a recibir los beneficios de los diferentes sistemas sociales o las salvaguardas que los estados y organismos han procurado para los ciudadanos legítimos.

De este modo, el discurso de la esfera pública se convierte en una pieza clave para la concepción del ser humano y es que, plagados de marcos categoriales que validan las estructuras de poder, el lenguaje filosófico se hace medio rancio, fúnebre y cómplice pues, se distrae en discusiones nominales, limitando su accionar a los espacios académicos o discursivos, haciendo de la experiencia humana una simple narrativa donde lo realmente preocupante es en el uso correcto del lenguaje categorial y donde la existencia concreta se vuelve narrativa, noticia o en el peor de los casos 
un 'meme'. Y es que, consecuentemente con lo antes expuesto, es inevitable reconocer, como lo expreso Wojtyla (2005), la tradición filosófica y científica, han hecho de la reflexión sobre el ser humano una situación nominal extrínseca a sí mismo, donde lo han situado como un objeto más en el mundo al cual pertenece.

Las ideas de Wojtyla (2005) permiten colegir que la objetividad entendida de esta manera conduce a una reducción o fraccionamiento de la persona, por lo que todo aquello que pueda valorarse en aras de su autonomía y unicidad es vejado, con lo cual se niega toda posibilidad a una valoración real de la subjetividad que es sinónimo de lo irrepetible de la persona humana, tal como lo expresa Ortega (2009): "la persona humana es subjetiva, pero al mismo tiempo la afirmación de su subjetividad es lo objetivo, en cuanto cada persona objetivamente es una existencia única e irrepetible que desde su subjetividad vive su existencia concreta" (p. 170).

Luego, es mandatorio romper con estas ontologías que exaltan lo categorial-nominal como única vía de aprehender la humanidad de la persona y adentrarse en una ontología de la existencia que interpela a valorar la singularidad, es decir, en dejar de mirar caras y mirar ese rostro que nos demanda una respuesta, un nombre propio, un encuentro con la vulnerabilidad del otro. Y es que, en la experiencia de la vulnerabilidad y el sufrimiento, tal como lo expresa Cavarero (2009):

La víctima siempre tiene un nombre, aunque el horror haya querido borrarlo. La víctima no es algo sino alguien. No se trata, ciertamente, de inventar un nuevo lenguaje, sino de mostrar que es la vulnerabilidad del inerme en cuanto específico paradigma epocal la que debe venir a primer plano en las escenas actuales (p.12).

Esta postura de reconocer al otro, de sentirme interpelado, va más allá de un mero acto de hablar sobre algo, sino más bien se trata de hablar con un alguien que acontece, que rompe la identidad del yo, el solipsismo de la razón, el egocentrismo del yo, la autosuficiencia. Este encuentro va más allá de lo categorial, pues como se advierte en la propuesta de Levinas (1994), ocurre como el desempalabramiento del yo y del mundo, es la imposibilidad de la comprensión, es el vértigo del sentido, es la respuesta adecuada que nunca lo es del todo.

Este encuentro solo puede ocurrir en la existencia; pero si algo ha enseñado la experiencia límite de la pandemia del Covid-19, es que el aislamiento que hoy se vive no es solo corpóreo sino ético, pues ha desvelado la magnitud de la marginalidad en que vive el otro, condenado a una existencia desestimada o, mejor dicho, sin sentido desde los marcos hegemónicos. 


\section{Del sentido de la existencia a la existencia egocéntrica posmoderna}

De manera general, se ha aceptado — casi unánimemente- que la existencia ocurre con un sentido, es más, se ha llegado a identificar dos grandes posturas al respecto, en las que no se profundiza en este documento, pero que no por ello deben ser dejadas de lado. La primera, que es la más común, es la que hace referencia a todo el trabajo de Frankl (1993) y donde establece que la forma de afrontar cada situación concreta está supeditada a factores externos al sujeto. La segunda posición, por el contrario, que es presentada por Sartre (1993), y se refiere a que es uno mismo quien inventa el sentido de su propia existencia.

Aunque ambas posiciones parecen muy diferentes, lo cierto es que el punto de encuentro es que la experiencia de la situación personal es intransferible. En palabras de Sartre (1993): "la situación de cada sujeto se presenta como única, sin posibilidad de ser comparada con la de otro, cada persona no realiza más que una situación: la suya" (p. 573).

Esta idea de la vivencia o experiencia de la propia vida no puede entenderse desde lo excluyente, lo solipsista, sino que debe entenderse en responsabilidad siempre en respuesta y encuentro. No obstante, como plantea Mejía (2010): "El hombre posmoderno (...) le basta con gozar la realidad del presente limitado; lo importante es lo que cada uno piensa, siente, necesita, cree, busca, experimenta, aunque esto sea provisional, momentáneo, parcial" (p. 70).

Pero, yendo un poco más allá, es posible caer en cuenta que este sujeto posmoderno es un constate buscador de la propia satisfacción individual que nace de su exacerbado amor a sí mismo y, paradójicamente, se puede constatar, en el plano de la experiencia, que aquello de lo que más carece este sujeto es de amor propio. Peor aún, este sujeto posmoderno no ha entendido que toda pregunta sobre el sentido de su vida es también una pregunta sobre la relación con otro y por el contrario se ha sumido en la confusión y que, a su vez, lo ha dejado en manos de la inseguridad de no conocerse y de no saberse único. Bauman (2006) dirá al respecto del sujeto posmoderno:

(...) la capacidad de "ir de compras" al supermercado de identidades y el grado de libertad -genuina o putativa- del consumidor para elegir una identidad y mantenerla tanto tiempo como lo desee se convierten en camino real hacia la concreción de las fantasías de identidad.

(...) En una sociedad de consumo, compartir la dependencia del consumo - la dependencia universal de comprar- es la conditio sine qua 
non de toda libertad individual; sobre todo, de la libertad de ser diferente, de tener identidad (p. 90).

Si algo también ha dejado muy en claro la pandemia del Covid-19, es este estado de autopreservación hedonista que se enraíza en una ética pobre, famélica y llena de costumbrismo. El ser humano posmoderno experimenta su vulnerabilidad no como experiencia de encuentro humanizante y humanizador en su mayoría, sino que se encierra en un estado de histeria tal que no reconoce al otro sino como un enemigo, como ese otro que le puede quitar el último rollo de papel higiénico que hay en la estantería del supermercado.

Sobre las últimas líneas del párrafo anterior, y aunque pueda sonar ridículo y absurdo lo planteado, en un reportaje investigativo que hiciera Bryan Lufkin y que apareció el 10 de marzo en el sitio web de la BBC, se narra lo siguiente:

En Auckland, Nueva Zelanda, el gasto en supermercados se disparó un $40 \%$ el sábado pasado en comparación con el mismo día de 2019. Los compradores en Malasia han causado un aumento del 800\% en las ventas semanales de gel antibacterial. Todos estos países tienen casos confirmados de Covid-19 (Lufkin, 2020).

Si bien es cierto que, se trata de explicar este comportamiento desde el ámbito psicológico, también es cierto que las reacciones egoístas han evidenciado una crisis ética en el ser humano posmoderno. Esta crisis ética al desconocer el valor central que es el ser humano ha carcomido los cimientos de una sociedad que acostumbrada a escándalos de corrupción y de malversación de fondos a niveles locales, estatales, gubernamentales y regionales, se distrae en los escenarios, programas y espectáculos que, parafraseando a Butler (2014), han sido creados seguir manteniendo el ocultamiento y el desinterés de las otras vidas, de otros cuerpos, de otros relatos y a cambio concentrarse en la satisfacción de las propias necesidades.

\section{De la lucha sanitaria al reconocimiento de un encuentro ontológico existencial humanizador}

Siguiendo el orden de ideas hasta este punto desarrollado, se hace preponderante el analizar lo que ocurre en la esfera de lo público y como sigue manejándose un discurso políticamente correcto, pero inhumanamente excluyente. En este sentido, no sorprende el escuchar que los gobiernos se han esforzado en presentar, permanentemente, cifras sobre su accionar a raíz de la crisis del Covid-19. Por ejemplo, algunos discursos 
evidencian como más de un $90 \%$ de las organizaciones estatales o nacionales y de la empresa privada han tomado medidas de prevención por el Covid-19 y que, de estas, tal vez más del 50\% dio su autorización para que sus colaboradores realicen teletrabajo desde sus casas.

Es más, habrá escuchado también que algunas de estas empresas han procurado proveer alcohol en gel y concientizar sobre el continuo lavado de manos. Asimismo, como una serie de encuestas y estudios realizado a expertos ha arrojado resultados como que. por ejemplo, el $60 \%$ de expertos encuestados sobre las repercusiones económicas del Covid-19 creen que la pandemia afectará a las compañías de manera muy profunda. En tanto, que el 36\% aseguran que solo será de manera moderada, mientras que para el 5\% no afectará económicamente.

Del otro lado también se maneja el discurso sensacionalista y desestabilizador, tal como aquellos que en medios masivos denuncian la incompetencia de pseudo líderes que ante la pandemia han sido incapaces de hacer cumplir las acertadas medidas dispuestas internacionalmente, en este sentido artículos como el que se publicó el 17 de abril en la página oficial del diario Panamá América (2020), ayudará a demostrar este punto:

Los efectos sobre la economía siguen siendo uno de los principales focos de la pandemia, que podría generar "otra década perdida (...) entre 2015 y 2025” en Latinoamérica, según advirtió este jueves el director del hemisferio occidental del Fondo Monetario Internacional (FMI), Alejandro Werner (...) la economía de América Latina y el Caribe se reducirá un 5,2\% este año por el impacto de la actual crisis sanitaria, un descenso más profundo que el de la economía mundial, que caerá un 3\%, según las previsiones presentadas esta semana por el FMI (p. 1).

Discursos y noticias como estas siguen invisibilizando a muchas personas, pues mientras se distrae al lector con números y porcentajes, se hace imposible preguntar por aquellos que, en toda la América Latina, intentan ganarse el sustento de su hogar a pesar de no tener un seguro social que los ampare, peor aún un trabajo regular, un sindicato que los apoye, o en algunos casos, un simple espacio donde guarecerse. Pero se sigue distrayendo a las masas con discursos como el que ofreció la agencia de calificación Fitch y que se publicó en el Diario Panamá América (2020) que: "puso a siete países de la región en perspectiva negativa por primera vez a raíz del impacto del Covid-19: Chile, Colombia, Uruguay, Panamá, Aruba, Costa Rica y Bolivia” (p. 1).

Discurso que se construyen y validan dentro de un marco hegemónico de poder, que hace imposible que el ser humano se pregunte por los 
niñas, niños y jóvenes que, atrapados de un sistema educativo caduco, no han podido seguir estudiando pues, aunque se les envió a sus casas, muchos de ellos viven en lugares carentes de luz eléctrica, internet o computadoras y como estos, muchos otros ejemplos más que otra vez recuerdan que las medidas preventivas y de protección fueron pensadas para ayudar aquellos que dentro de los marcos hegemónicos, ostentan la dignidad de personas, de ciudadanos y que, lamentablemente, respaldados por una existencia líquida, egocéntrica y ensimismada, no hacen más que validar este sistema.

Si algo ha mostrado esta pandemia es, como bien afirma Santamaría (2020) es:

...como cualquier situación límite, nos obliga a pensar no solo en el virus, también nos empuja a interpretar todo el contexto alrededor (este caso global), establecer relaciones no obvias (no solo con la ciencia médica) y poner en duda los valores sobre los que hemos levantado la frágil civilización humana. De hecho, por la situación misma varios ideales que han sostenido nuestra economía, nuestras instituciones políticas, nuestras relaciones globales, etc., parecen tambalear (p.1).

\section{A manera de conclusión}

A lo largo de toda esta reflexión, se ha pretendido sustentar la necesidad de reconocer que, si bien es cierto, todos en esta situación de pandemia han experimentado, en mayor o menor grado, una situación de vulnerabilidad, esta experiencia debería ser un primer momento que invite a cada persona a replantear la propia vida. Más allá de ello, un punto de quiebre que, al desestabilizar los modelos caducos, haga posible plantear la pregunta sobre el sentido de la vida y el lugar que el otro ocupa en esa respuesta repuesta.

$\mathrm{Y}$ es que al demostrar que la vulnerabilidad puede ser considerada como experiencia dialógica que interpela al encuentro y que demanda una humanización, también es cierto que dentro de los diferentes marcos categoriales en los que el sistema hegemónico coloca a cada ser humano, se debe provocar una irrupción ontológica desde esta experiencia de la vulnerabilidad.

Esta ontología de la vulnerabilidad que, también dotada de posibilidad epistemológica, propicia y aprende la vida que, si bien es cierto se vive relacionada con las normas de producción de sujetos y con el reconocimiento, debe ser espacio dialógico suficiente que desafía a los marcos hegemónicos. Pues, como afirma Butler (2010): "la producción normativa de la ontología produce el problema epistemológico de aprehender 
una vida" (p. 16), que no puede limitarse solo al orden de la percepción o del conocimiento, sin incluir la reciprocidad del reconocimiento del otro, no como un galardón sino como un conocer nuevamente, como un compartir desde la profundidad de la existencia. Y es que como manifiesta Butler (2010) en su obra Marcos de guerra:

Si se produce una vida según las normas por las que se reconoce la vida, ello no implica ni que todo en torno a una vida se produzca según tales normas ni que debamos rechazar la idea de que existe un resto de vida — suspendida y espectral — que describe y habita cada caso de vida normativa (p. 22).

Finalmente, y teniendo claro que hay posibilidad en un ápice de vida suspendida y espectral, es necesario aferrarse a provocar una irrupción ontológica que desafíe y replantee la vida, la ética y el sentido de la existencia en relación con un otro.

Superar la pandemia del Covid-19 no se trata de volver a la 'normalidad' de la vida sino, de aprenderla de tal manera que sea posible aprovechar los espacios espectrales que se den o que se provoquen, para dar voz a los que siguen quedando fuera de los marcos hegemónicos; pues si no se aprovecha este breve momento en el tiempo, la humanidad se quedará solo como una espectadora; como aquellos que cautivados por cómo la naturaleza ha reclamado espacios en los canales de Venecia, comienzan hacer planes de hacer una visita turística y postear la mejor foto en busca de la mayor cantidad de likes, pero que volverán a ser la causa de la destrucción de los ecosistemas, allí y en el resto del hogar común, al que se ha llamado Tierra.

\section{Notas}

1 https://who.maps.acgis.com/

2 Instituto de Estadística de la Unesco: http://data.uis.unesco.org/

\section{Bibliografía}

ARENDT, Hannah

1968 La filosofía de la existencia. Memoria Académica, 48-68. Recuperado de: https://bit.ly/38YDi4L

BAUMAN, Zygmunt

2006 Modernidad líquida. Buenos Aires: Fondo de Cultura Económica. BUTLER, Judith

2006a Deshacer el género. Barcelona: Paidós. 
2006b Vida precaria: El poder del duelo y la violencia. Buenos Aires: Paidós.

2010 Marcos de guerra. México: Paidós.

2012 Llevarnos a la pena: Judith Butler y la política del duelo. Political Theory, 409-436.

2014 ¿Qué es una buena vida? Paris: Payot.

CAVARERO, Adriana

2009 Horrorismo. Barcelona: Anthropos.

FERNÁNDEZ, Carlos

2009 Derecho de las personas. Lima: Grijley.

FOUCAULT, Michel

2000 Vigilar y castigar. España: Siglo XXI.

FRANKL, Viktor

1993 El hombre en busca de sentido. Barcelona: Herder.

GUTIÉRREZ SÁENZ, Raúl

1999 Historia de las doctrinas filosóficas. México: Esfinge.

INTERNATIONAL FEDERATION OF RED CROSS AND RED CRESCENT SOCIETIES

2020 Recuperado de: https://www.ifrc.org/

JASPER, Karl

1950 Introducción a la Filosofía. Madrid: Cátedra

LA GACETA DE SALAMANCA

2020 La Gaceta de Salamanca. Recuperado de: https://bit.ly/2X5RFip

LEVINAS, Emmanuel

1993 El tiempo y el otro. Barcelona: Paidós.

1994 Dios, la muerte y el tiempo. Madrid: Cátedra.

2006 Paz y proximidad. Laguna: Revista de Filosofía, 18, 143-154. Recuperado de: https://bit.ly/393QRjH

LUFKIN, Berik

2020 Coronavirus: la psicología detrás de las compras nerviosas por el brote de Covid-19. BBC News. Recuperado de: https://bbc.in/353O3Sn

MALAMUD, Carlos \& NÚNEZ, Rogelio

2020 El Covid-19 en América Latina: desafíos políticos, retos para los sistemas sanitarios e incertidumbre económica. Real Instituto El Cano. Recuperado

MEJÍA, Álvaro de: https://bit.ly/3pORXqc

2010 Un paradigma eclesiológico para la postmodernidad. Medellín: Fundación Universitaria Luis Amigó.

ORTEGA, Remberto \& FERNÁNDEZ, Johny

2014 La Ontología de la Educación como un referente para la comprensión de sí misma y del mundo. Sophia: Colección de Filosofía de la Educación 17(2), 37-57. https://doi.org/10.17163.soph.n17.2014.15

ORTEGA, Remberto

2009 La objetividad de la subjetividad de la persona: El reto de educar en valores en un mundo relativista. Sophia: Colección de Filosofía de la Educación, 165186. Recuperado de: https://bit.ly/2KXNItq

PACHECO, Vicente

2017 Poblaciones vulnerables y en situación de vulnerabilidad. Comisión Nacional de Bioética en Salud Redbioética UNESCO para América Latina y el Caribe. Quito, Ecuador. 
PANAMÁ AMÉRICA

2020 Diario Panamá América. https://bit.ly/2XbgPw6

SANTAMARÍA, Jaime

2020 Filosofía \& Co. Obtenido de Revista de Filosofía \& Co. https://www.filco.es/.

SARTRE, Jean Paul

1993 El ser y la nada. Barcelona: Altaya.

UNESCO

1994 Declaración Universal de los Derechos Humanos de las Generaciones Futuras. UNESCO.

UNICEF

2020 UNICEF. Recuperado de: https://uni.cf/3ndVbSv

VARSI, Enrique

2017 Clasificación del sujeto de derecho frente al avance de la genómica y la procreática. Originales: Acta de Bioethica (pp. 213-225). Lima: Universidad de Lima.

VÉLEZ, Paul

2015 ¿Ontología u ontologías? Disputatio. Philosophical Research Bulletin, 4(5), 299-339. Recuperado de: https://bit.ly/355cgrd

VILLA, Miguel

2001 Vulnerabilidad social. Seminario Internacional: Las diferentes expresiones de la vulnerabilidad en América Latina y el Caribe. Santiago, Chile.

WOJTYLA, Karol

2005 El hombre y su destino. Madrid: Palabra.

Fecha de recepción de documento: 3 de mayo de 2020

Fecha de revisión de documento: 15 de junio de 2020

Fecha de aprobación de documento: 20 de agosto de 2020

Fecha de publicación de documento: 15 de enero de 2021 